EXTENDED REPORT

\title{
Differential effect of ILIO and TNF $\alpha$ genotypes on determining susceptibility to discoid and systemic lupus erythematosus
}

A Suárez, P López, L Mozo, C Gutiérrez

See end of article for authors' affiliations

Correspondence to: Dr Carmen Gutiérrez, Servicio de Inmunología, Hospital Universitario Central de Asturias, Julián Clavería s/n, 33006 Oviedo, Spain; carmen. gutierrezm@sespa. princast.es

Accepted 24 March 2005 Published Online First 30 March 2005
Objective: To ascertain the possible involvement of functional interleukin 10 (IL10) and tumour necrosis $\alpha$ (TNF $\alpha$ ) cytokine promoter polymorphisms on the susceptibility to discoid and systemic lupus erythematosus (DLE, SLE), and their associations with immunological features.

Methods: Single nucleotide polymorphisms of the ILIO $(-1082,-819$, and -592$)$ and TNF $\alpha(-308)$ genes were determined using allele specific probes in 248 lupus patients and 343 matched controls. To assess functional significance of genotypes, basal mRNA cytokine levels were quantified in 106 genotyped healthy controls by real time RT-PCR. Specific autoantibodies and cutaneous manifestations were analysed in SLE patients and associated with functional genotypes.

Results: After analysing the distribution of IL10 and TNF $\alpha$ transcript levels according to promoter genotypes in healthy individuals, patients and controls were classified into functional single and combined genotypes according to the expected high or low constitutive cytokine production. High TNF $\alpha$ genotypes $(-308 \mathrm{AA}$ or AG) were associated with SLE independently of IL10 alleles, whereas the risk of developing DLE and the prevalence of discoid lesion in SLE were higher in the high IL10/low TNF $\alpha$ producer group (-1082GG/-308GG). Cytokine interaction also influences the appearance of autoantibodies. Antibodies against $\mathrm{Sm}$ are prevalent among low producer patients for both cytokines, a genotype not associated with lupus incidence, whereas low IL10/high TNF $\alpha$ patients have the highest frequency of antibodies to SSa and SSb.

Conclusions: IL10/TNF $\alpha$ interaction influences susceptibility to DLE and the appearance of specific autoantibodies in SLE patients, whereas high TNF $\alpha$ producer genotypes represent a significant risk factor for SLE.
S ystemic lupus erythematosus (SLE) is a disorder of immune regulation resulting in a chronic inflammation that affects many organs. Discoid lupus erythematosus (DLE) is a limited skin variant responsible for $50-85 \%$ of cutaneous lupus diseases. Although early lesions may be difficult to distinguish from subacute cutaneous lupus erythematosus (SCLE), discoid lesions are characteristic and may also occur in SLE patients. DLE patients rarely have systemic disease, and progression to SLE is uncommon (less than 5\%), whereas SCLE patients often fulfil four or more of the criteria used to classify SLE. All these conditions tend to run in families and probably occur in genetically predisposed individuals, but the precise genetic connections of each variant have not been yet determined.

The production of two regulators of the inflammatory reaction-interleukin 10 (IL10) and tumour necrosis $\alpha$ (TNF $\alpha$ ) - has been found to be deeply deregulated in SLE, suggesting that these regulators may be involved in the pathogenesis of the disease. High levels of ILl0 have been reported in the serum of lupus patients, ${ }^{1-4}$ suggesting a high baseline production state. A more controversial issue is the involvement of TNF $\alpha$ in the pathogenesis of lupus, although most investigators have found increased levels in patient sera. ${ }^{56}$ Genetic polymorphisms at the promoter of IL10 and TNF $\alpha$ genes have been associated with different forms of cytokine production after in vitro lymphocyte stimulation. Although there are no previous reports on the influence of these genes, we believe that variations in basal IL10 and $\mathrm{TNF} \alpha$ production may influence disease susceptibility by modulating an initial immune response to in vivo autoantigen encounter.
The ILl0 gene promoter has been shown to be very polymorphic. In addition to two microsatellites, there are three single nucleotide polymorphisms (SNPs) at positions $-1082(\mathrm{G} / \mathrm{A}),-819(\mathrm{C} / \mathrm{T})$, and $-592(\mathrm{C} / \mathrm{A})$ generating three haplotypes (GCC, ACC, and ATA) associated with variability in IL10 production. ${ }^{78}$ Various reports have analysed the influence of these polymorphisms on lupus disease, with conflicting results. The IL10.G microsatellite has been associated with SLE incidence in Scottish, ${ }^{9}$ MexicanAmerican, ${ }^{10}$ and Italian, ${ }^{11}$ but not in Mexican, ${ }^{12}{ }^{13}$ Swedish, ${ }^{13}$ or Taiwanese ${ }^{14}$ populations. The frequency of $-1080 \mathrm{G}^{*}$ allele was increased in Vietnamese SLE patients, ${ }^{15}$ and carriage of the GCC haplotype has been linked to renal involvement and synthesis of SSa antibodies in white British patients, ${ }^{16}$ while the ATA haplotype was overrepresented among white Dutch patients with neuropsychiatric lupus ${ }^{17}$ and Chinese patients suffering from renal disorder. ${ }^{18}$ However, these haplotypes have not been found to be strong determinants of susceptibility to lupus disease in white populations. ${ }^{16-22}$

Among the various polymorphisms described at the TNF $\alpha$ promoter, the genetic variant at position -308(G/A) was found to have functional effects on gene transcriptional activity, the uncommon TNF2 allele $\left(-308 A^{*}\right)$ being a stronger transcriptional activator than $-308 \mathrm{G}^{*}$ after in vitro lymphocyte stimulation. ${ }^{23}{ }^{24}$ Various studies have analysed the association between $\mathrm{TNF} \alpha$ alleles and lupus, with

Abbreviations: ACR, American College of Rheumatology; DLE, discoid systemic lupus erythematosus; RT-PCR, reverse transcriptase polymerase chain reaction; SLE, systemic lupus erythematosus; SNP, single nucleotide polymorphism 
inconclusive results. An increased risk of developing SLE, independent of the HLA-DR genotype, has been reported for carriers of TNF2 allele in Dutch, ${ }^{25}{ }^{26}$ African American, ${ }^{27}$ and North American white populations. ${ }^{28}$ However, no relation was found in other work analysing mestizo Mexicans, ${ }^{29}$ North American whites, ${ }^{30}$ and African Americans. ${ }^{28} \mathrm{~A}$ significant association has also been reported between TNF2 and anti-SSa positive SCLE, but not with DLE. ${ }^{22}$

The genetic control of constitutive IL10 and TNF $\alpha$ production and the possible interaction between the two cytokines in influencing lupus susceptibility has not yet been evaluated. Our aim in the present study was to investigate the influence of functional cytokine genetic variants and their interactions in conditioning the occurrence of DLE and SLE in a Spanish population. The relation with autoantibody synthesis in SLE was also examined.

\section{METHODS \\ Patients}

The study population included 248 lupus patients (table 1) and 343 matched healthy individuals, all of white origin. Fifty six patients were diagnosed as having DLE by clinical and histological examination of the characteristic discoid lesion and after excluding features of systemic involvement. In the other 192 patients a diagnosis of SLE was established according to the American College of Rheumatology (ACR) criteria. $^{31}$ In 164 of these patients the appearance of cutaneous manifestations during the course of the illness was analysed.

The Hospital Universitario Central de Asturias ethics committee gave ethical approval for the study.

\section{Promoter polymorphisms genotyping}

Genomic DNA was extracted from blood samples by standard procedures. SNPs at positions -1082 and -592 of the IL10 gene and at position -308 of the TNF $\alpha$ gene were determined by analysing the $\mathrm{Tm}$ of the probe/target duplex after polymerase chain reaction (PCR) amplification and hybridisation with fluorescent labelled probes matched with one sequence variant (LightCycler, Roche Diagnostics, Mannheim, Germany), using previously validated methods. ${ }^{32}$ Primers employed were: ATCCAAGACAACACTACTAAGGC and ATGGGGTGGAAGAAGTTGAA for - 1082; GGTGAGCACTACCTGACTAGC and GCAGCCCTTCCATTTTACTTTC for -592; and CCTGCATCCTGTCTGGAAGTTA and CTGCA CCTTCTGTCTCGGTTT for -308. Hybridisation probes (designed by TIB Molbiol, Berlin, Germany) were: GGATAGGAGGTCCCTTACTTTCCTCTTACC-F and LC Red 640-СССТАСТTCССССТCССAAA for -1082; AGCCTGGAA CACATCCTGTGACCCC-F and LC Red 640-CCTGTCCTGTAG

Table 1 Patient characteristics

\begin{tabular}{ll}
\hline All patients & 248 \\
\hline & \\
DLE & 56 \\
Age at diagnosis (years) (median/IQR) & $40.0 / 17.2$ \\
Female & $40(71.4 \%)$ \\
SLE & 192 \\
Age at diagnosis (years) (median/IQR) & $32.0 / 20.0$ \\
Female & $179(93.2 \%)$ \\
Presence of autoantibodies (\%): & 30.6 \\
$\quad \begin{array}{l}\text { anti-SSa } \\
\text { anti-SSb }\end{array}$ & 14.4 \\
$\quad \begin{array}{l}\text { anti-RNP } \\
\text { anti-Sm } \\
\text { anti-dsDNA }\end{array}$ & 13.3 \\
\hline $\begin{array}{l}\text { Values are } n \text { or } n \text { (\%) unless stated otherwise. } \\
\text { DLE, discoid systemic lupus erythematosus; IQR, interquartile range; SLE, }\end{array}$ \\
\hline
\end{tabular}

GAAGCCAGTCTC for -592; and AACCCCGTCCCCATGCCCC$F$ and LC Red 640-CCAAACCTATTGCCTCCATTTCTTTT GGGGAC for -308 . Allele present at -819 IL10 was assigned directly owing to the total linkage with the -592 allele in our population. After analysing alleles at the three IL10 promoter sites we found only six genotypes, which corresponded to the three haplotypes previously described in other white populations.

\section{mRNA isolation and quantification}

Sample mRNA (poli-A+) was isolated from whole blood using the mRNA isolation kit for blood/bone marrow (Boehringer Mannheim, Mishawaka, Indiana, USA). Reverse transcription was carried out by standard procedures. Real time reverse transcriptase polymerase chain reaction (RT-PCR) (LightCycler, Roche Diagnostics) was used to quantify cytokine mRNA by monitoring the fluorescence emitted by SYBR Green I dye, using an external standard (cDNA obtained from lipopolysaccharide stimulated peripheral blood mononuclear cells) to generate a calibration curve. $\beta_{2}$ Microblobulin was used as the housekeeping gene, enabling determination of mRNA relative units. Primers employed were: AGCTGAGAACCAAGACCCAGA and GGGCTGGGTCAGCTATCC for ILI0; ACAAGCCTGTAGCC CATGT and AAAGTAGACCTGCCCAGACT for TNF $\alpha$; and CCAGCAGAGAATGGAAAGTC and GATGCTGCTTACATGT CTCG for $\beta_{2}$ microglobulin.

\section{Immunological assessment}

Anti-dsDNA antibodies were quantified by radioimmunoassay (Trinity Biotech, Bray, Wicklow, Ireland) or enzyme linked immunosorbent assay (ELISA) (ELIA, Pharmacia, Freiburg, Germany). The presence of anti-Ro/SSa, anti-La/ $\mathrm{SSb}$, anti-RNP, or anti-Sm antibodies was detected by ELISA screening (Orgentec, Maintz, Germany) and positive samples were analysed by immunoblotting (Inno-Lia, Innogenetics, Gent, Belgium) or specific ELISA (Orgentec).

\section{Statistical analysis}

Genotype frequencies of each SNP were analysed by the $\chi^{2}$ test to determine that they conformed to Hardy-Weinberg equilibrium based on the observed allele frequencies. Allele and genotype frequencies between patient and control groups and the presence of autoantibodies between patient subpopulations were compared using the $\chi^{2}$ test and the two tailed Fisher's exact test when the number of expected cases was small. Basal IL10 and TNF $\alpha$ mRNA expression and age at diagnosis were not distributed normally, so non-parametric testing was used throughout (Mann-Whitney U test or Kruskal-Wallis test). The strength of the association between functional single or combined genotypes and disease was assessed by unconditional logistic regression analysis, calculating odds ratios (OR) and 95\% confidence intervals (CI). Single locus regression models were run to estimate separately the effects of cytokine polymorphisms, comparing the high producer genotypes with the most common low producers. A combined two loci model was developed including both cytokine polymorphisms to estimate individual effects of each combined genotype, using the common low/low producer genotype as reference. The SPSS 11.0 statistical software package (SPSS Inc, Chicago) was used for all calculations.

\section{RESULTS}

\section{IL 10 and TNF $\alpha$ promoter polymorphisms}

An overrepresentation, at the limit of significance, of the genotype GCC/GCC at the IL10 promoter was observed in the whole lupus population when comparing with controls. The frequency of $-308 \mathrm{~A}^{*}$ allele at the TNF $\alpha$ gene was 
Table 2 Distribution of IL10 and TNF $\alpha$ promoter genotypes in healthy Spanish controls and patients with lupus erythematosus

\begin{tabular}{|c|c|c|c|c|c|c|c|}
\hline & \multirow{2}{*}{$\begin{array}{l}\text { Controls } \\
(n=343)\end{array}$} & \multicolumn{2}{|c|}{ All patients $(n=248)$} & \multicolumn{2}{|l|}{ SLE ( $n=192)$} & \multicolumn{2}{|c|}{ DLE $(n=56)$} \\
\hline & & n (\%) & $p$ Value & n (\%) & p Value & n $(\%)$ & p Value \\
\hline \multicolumn{8}{|l|}{ IL10 (-1082, $-819,-592)$} \\
\hline ATA/ATA & $31(9.0)$ & $22(8.9)$ & 0.944 & $11(8.3)$ & 0.782 & $6(10.7)$ & 0.688 \\
\hline ATA/ACC & $64(18.7)$ & 35 (14.1) & 0.144 & $31(16.1)$ & 0.466 & $4(7.1)$ & 0.035 \\
\hline ACC/ACC & $39(11.4)$ & $28(11.3)$ & 0.976 & $22(11.5)$ & 0.975 & $6(10.7)$ & 0.886 \\
\hline GCC/ATA & $58(16.9)$ & $35(14.1)$ & 0.357 & $28(14.6)$ & 0.482 & $7(12.5)$ & 0.407 \\
\hline GCC/ACC & $100(29.2)$ & $76(30.6)$ & 0.696 & $58(30.2)$ & 0.798 & $18(32.1)$ & 0.650 \\
\hline GCC/GCC & $51(14.9)$ & $52(21.0)$ & 0.054 & $37(19.3)$ & 0.188 & $15(26.8)$ & 0.026 \\
\hline$-1082 G^{*}$ & $37.90 \%$ & $43.35 \%$ & 0.059 & $41.67 \%$ & 0.226 & $49.11 \%$ & 0.024 \\
\hline$-819 \mathrm{~T} /-592 \mathrm{~A}^{*}$ & $26.82 \%$ & $22.98 \%$ & 0.134 & $23.70 \%$ & 0.262 & $20.54 \%$ & 0.151 \\
\hline \multicolumn{8}{|l|}{ TNF $\alpha(-308)$} \\
\hline $\mathrm{AA}$ & $7(2.0)$ & $11(4.4)$ & 0.095 & $7(3.6)$ & 0.272 & $4(7.1)$ & 0.054 \\
\hline GA & $71(20.7)$ & $84(33.9)$ & $<0.0001$ & 72 (37.5) & $<0.0001$ & $12(21.4)$ & 0.901 \\
\hline GG & 265 (77.3) & $153(61.7)$ & $<0.0001$ & $113(58.9)$ & $<0.0001$ & $40(71.4)$ & 0.340 \\
\hline$-308 A^{*}$ & $12.39 \%$ & $21.37 \%$ & $<0.0001$ & $22.40 \%$ & $<0.0001$ & $17.86 \%$ & 0.113 \\
\hline
\end{tabular}

The significance was evaluated by $\chi^{2}$ test or two tailed Fisher's exact test.

DLE, discoid systemic lupus erythematosus; IL10, interleukin 10; SLE, systemic lupus erythematosus; TNF $\alpha$, tumour necrosis factor $\alpha$.

significantly increased in patients compared with controls (table 2). When lupus subtypes were analysed separately, DLE was associated with $-1082 \mathrm{G}^{*}$ IL10 but not with TNF $\alpha$ alleles, whereas SLE remained highly associated with $-308 A^{*}$ allele but not with IL10 SNPs.

To determine the possible influence on disease susceptibility of variations in constitutive IL10 and TNF $\alpha$ production, we quantified basal cytokine mRNA levels in 106 healthy genotyped subjects and analysed the distribution of transcript levels according to promoter genotypes. Despite important interindividual variations, we found that individuals homozygous for the GCC haplotype are the highest producers of basal IL10, showing significant differences when compared with individuals who were homozygous or heterozygous for the ACC or ATA haplotypes, indicating that the -1082 position was relevant for constitutive IL10 production (fig 1A). Similarly, individuals carrying the genotype $-308 \mathrm{GG}$ at the TNF $\alpha$ gene have reduced transcript levels compared with the other two genotypes (fig 1B).

\section{Functional genotypes and lupus susceptibility}

On the basis of these findings, patients and controls were classified into high and low functional genotypes according to the expected constitutive mRNA levels (table 3). Additionally, in order to analyse putative IL10/TNF $\alpha$ interactions, individuals were classified into the four possible functional combined genotypes. The single locus model study showed that high IL10 producer genotype was significantly overrepresented in DLE, whereas a predisposition to develop SLE was found among those carrying the high TNF $\alpha$ producer allele. Analysis of the combined IL10/TNF $\alpha$ genotypes yielded a different distribution in patients and controls $(\mathrm{p}=0.00008$, $4 \times 2$ contingency table). When analysing the influence of combined genotypes on the appearance of lupus subtypes, we found that carriage of the TNF2 allele was associated with SLE independently of the IL10 genotype $(p=0.394$, $2 \times 2$ contingency table). However, a significant influence of IL10/TNF $\alpha$ interaction was detected in determining DLE susceptibility. Logistic regression modelling for combined genotypes showed that high IL10/low TNF $\alpha$ producers had a stronger association with DLE than the whole high IL10 group.

On the basis of these results, we studied the possible involvement of IL10 in the appearance of skin disease in SLE patients. We analysed the influence of IL10 genotypes on the appearance of phosensitivity, malar rash, and discoid and subacute cutaneous lesions in patients with low TNF $\alpha$ genotype. Table 4 shows that carriage of the high ILl0 genotype increased the prevalence of discoid lesions, but not other cutaneous manifestations. No significant effect of IL10 genotype on skin lesions was found among high TNF $\alpha$ patients (data not shown).
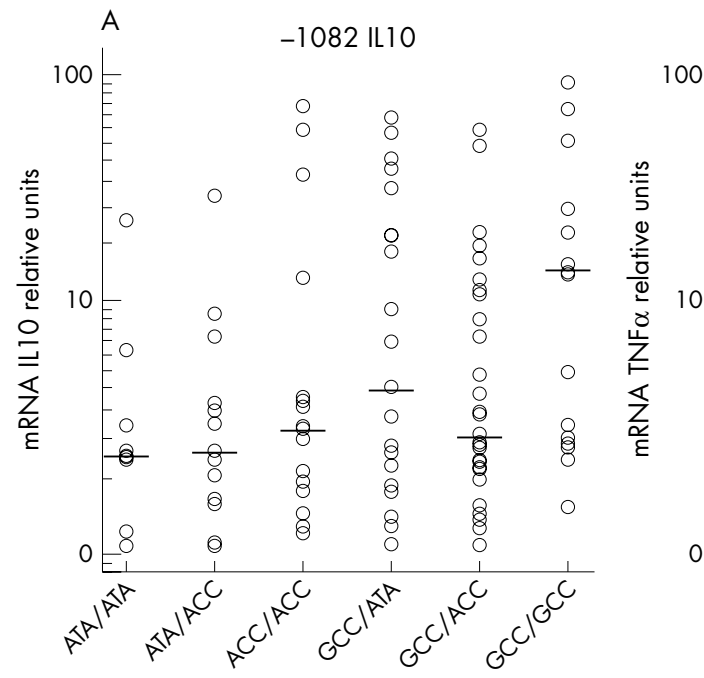

B

10

$\circ$

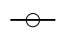

E-

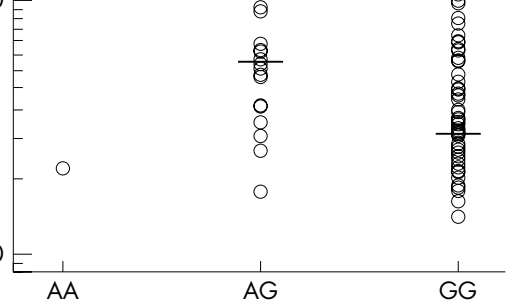

Figure 1 Relation between IL10 and TNF $\alpha$ genotypes and constitutive cytokine expression. Interleukin 10 (IL10) (panel A) and tumour necrosis factor $\alpha$ (TNF $\alpha$ ) (panel B) basal mRNA levels were quantified in peripheral blood cells of 106 genotyped healthy subjects by a highly sensitive real time RT-PCR technique, as described in Methods. The distribution of transcript levels according to promoter genotypes was analysed. Horizontal bars are median values. Significance was evaluated by the Mann-Whitney U test: IL10 GCC/GCC $v$ other genotypes, $p=0.026 ; T N F \alpha G G$ vother genotypes, $\mathrm{p}=0.021$. 


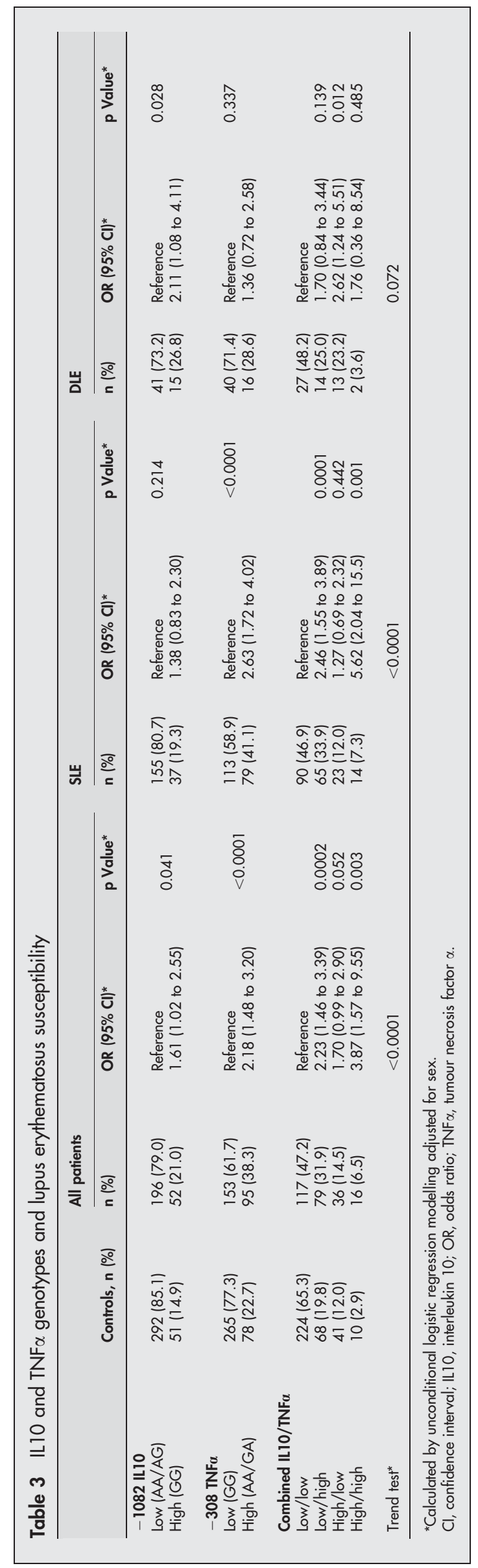

Table 4 Influence of IL10 polymorphism on the appearance of skin disease in SLE patients with low TNF $\alpha$ genotype

\begin{tabular}{|c|c|c|c|}
\hline & $\begin{array}{l}\text { Low IL10 } \\
(n=72)\end{array}$ & $\begin{array}{l}\text { High IL } 10 \\
(n=21)\end{array}$ & $p$ Value \\
\hline Photosensitivity & $40(55.6 \%)$ & $13(61.9)$ & 0.605 \\
\hline Malar rash & $36(54.2 \%)$ & 11 (52.4) & 0.885 \\
\hline Discoid lesions & $9(12.5 \%)$ & $7(33.3)$ & 0.044 \\
\hline Subacute cutaneous lesions & $12(16.7 \%)$ & $2(9.5)$ & 0.729 \\
\hline
\end{tabular}

\section{Cytokine polymorphisms and autoantibody production in SLE patients}

When combined genotypes were studied in relation to the presence of autoantibodies in SLE patients (table 5), we found the highest prevalence of anti-Sm antibodies among low IL10/ low $\mathrm{TNF} \alpha$ producers, but no relation was detected when analysing each cytokine individually. A significant influence of combined genotypes was also observed on the production of antibodies against SSb and, especially, SSa. High TNF $\alpha$ genotype was associated with SSa synthesis (44.3\% v 22.1\%, $\mathrm{p}=0.001)$, but significance was not reached with low IL10 producers $(34.2 \% v 18.9 \%, \mathrm{p}=0.072)$. Analysis of the combined genotypes showed a strong association with low IL10/high $\mathrm{TNF} \alpha(49.2 \% \quad v 22.1 \%, \mathrm{p}=0.00012)$, indicating that both cytokine genes contribute to the SSa phenotype. Anti-dsDNA antibodies were more abundant among high/high producers, although this finding was not statistically significant $(85.7 \% \mathrm{v}$ $64.6 \%, p=0.108$ ). Curiously, this combined genotype, infrequent in our population (7.3\% in SLE), was carried by three of the 13 male patients included in the study, suggesting a different genetic component of male SLE.

\section{DISCUSSION}

We have found a relation between polymorphisms at the promoter region of TNF $\alpha$ and ILl0 genes and the appearance of lupus disease in white Spaniards. Genetic variants at the promoter regions of these cytokine genes have been correlated with variations in mitogen induced transcriptional activity and cytokine synthesis in vitro, ${ }^{723} 24$ thus modulating the immune response after antigen challenge. Various cell types are constitutively capable of producing detectable amounts of these cytokines-mainly cells of myeloid origin and less abundantly $\mathrm{T}$ and $\mathrm{B}$ lymphocytes. Individual steady state levels of IL10 and TNF $\alpha$ may deviate an initial immune response towards different forms of $\mathrm{T}$ cell activation, influencing the susceptibility to transform a limited autoimmune response into an autoimmune disease. It is not known whether constitutive levels of ILl0 and TNF $\alpha$ are genetically controlled, and their putative influence on the appearance of lupus is also unknown. To this end, we first measured basal ILI0 and TNF $\alpha$ mRNA in blood cells from healthy subjects using a sensitive RT-PCR technique, and analysed their association with single nucleotide polymorphisms. Correlation with cytokine protein levels could not be undertaken, as many serum samples were below the detection limit of the assay. An association was found between the GG genotype at the - 1082 IL10 position and high transcript levels, whereas large amounts of TNF $\alpha$ mRNA were associated with carriers of the $-308 A^{*}$ allele. These findings allowed us to define functional constitutive genotypes and to classify patients and controls as high or low IL10 and TNF $\alpha$ producers. We found that the presence of the high producer TNF2 allele caused a substantial increase in the occurrence of SLE, whereas the incidence of DLE in a 
Table 5 Prevalence of autoantibodies in patients with systemic lupus erythematosus, distributed in functional genotypes

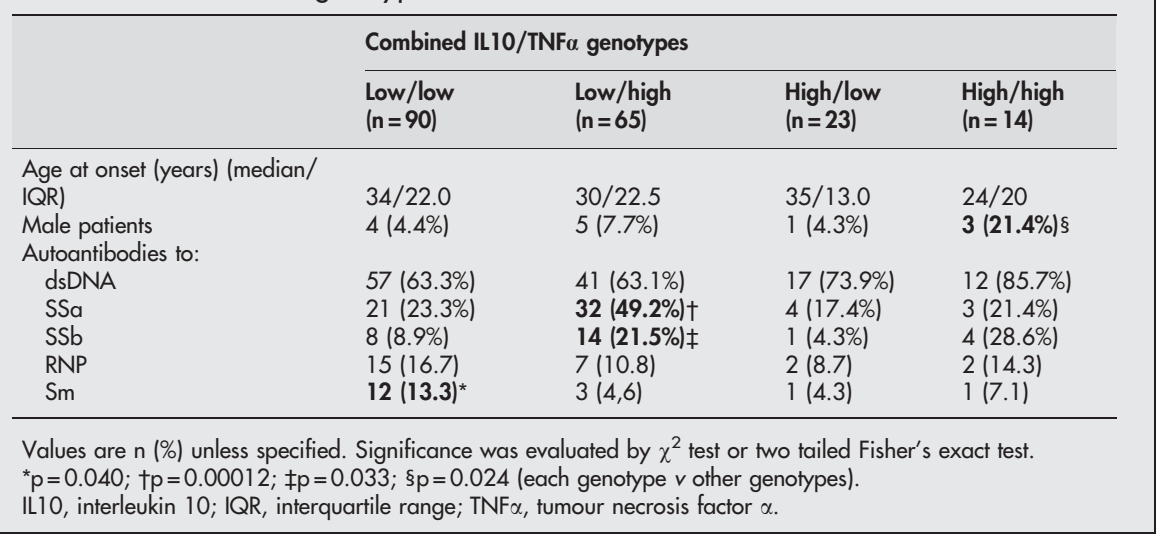

single cytokine analysis seemed not to be influenced by TNF $\alpha$ genotypes. The opposite occurred when analysing IL10 genotypes. Interestingly, we found for the first time a significant correlation of the high ILl0 genotype with the appearance of DLE, but not SLE.

Various mechanisms may be involved in the detrimental effect of TNF $\alpha$ in SLE. Because of its marked proinflammatory properties, it is quite plausible that high genetically sustained production, acting on an autoimmune-prone genetic background, resulted in the maintenance and amplification of an initial immune response to unknown self peptides. TNF $\alpha$ also has numerous effects on $\mathrm{T}$ and $\mathrm{B}$ lymphocytes, involving several immune functions. In a murine model, TNF $\alpha$ participates in autoimmune processes linked to inappropriate lymphocyte survival ${ }^{33}$; however, this cytokine is also a highly active promoter of the apoptotic process. It has been reported that sera from SLE patients react with proteins phosphorylated during apoptosis, ${ }^{34}$ probably by recognising new epitopes generated by phosphorylation or proteolysis. ${ }^{35}$ Because of the proapoptotic properties of TNF $\alpha$, probably enhanced in SLE patients by their raised concentrations of IFN $\alpha^{36}{ }^{37}$ high levels of this cytokine may trigger an autoimmune response to antigenically modified autoproteins generated during the apoptotic process. An alternative to the pathogenic role of TNF2 in SLE is that it could be a marker for the extended haplotype HLAAl B8 DR3, which is strikingly associated with SLE and other autoimmune conditions. Nevertheless, carriage of TNF2 allele-in the presence or absence of other loci-leads to an increase in $\mathrm{TNF} \alpha$ production, thus modifying cytokine homeostasis in favour of the development of pathogenic situations. In addition, several studies have shown that both TNF2 and HLA-DR3 contribute independently to SLE susceptibility. ${ }^{21}{ }^{25-27}$

No previous studies have reported an association of IL10 alleles with susceptibility to DLE. van der Linden $e a^{21}$ found higher frequencies of the $-1082 \mathrm{G}^{*}$ allele in DLE than in SLE patients $(57 \% \vee 45 \%)$, although the difference was not statistically significant, probably because of the reduced number of patients included in the study. Interestingly, Alarcon-Riquelme et $a l^{12}$ found an association tendency between mucocutaneous manifestations in SLE patients and the IL10.G locus, which is in a weak linkage disequilibrium with the -1082 polymorphism. ${ }^{38}$ These findings indicate a probable role of IL10 in triggering discoid lesions. IL10 is a highly pleiotropic lymphokine that may act as a potent suppressor of systemic inflammatory responses while, on the other hand, inducing inflammation when overexpressed locally. This cytokine is constitutively expressed in a range of cellular populations, ${ }^{39}$ including keratinocytes, in which IL10 production is incremented in response to ultraviolet irradiation. ${ }^{40}$ Moreover, it has been shown that following UVB exposure, IL10 stimulates dermal endothelial cells to produce proinflammatory cytokines and chemokines $^{41}$ suggesting that genetically high ILl0 production could be responsible for discoid lesions. As support for this hypothesis, it is worth noting the finding that cutaneous manifestations improved in all SLE patients soon after initiating anti-IL10 monoclonal antibody treatment. ${ }^{42}$

The isolated assessment of cytokine genotypes, though of relevance, may not provide a realistic picture of their influence on lupus disease. The actions of cytokines may be profoundly conditioned by the presence of other cytokines, particularly in the case of IL10 and TNF $\alpha$, which have complex and predominantly opposing roles in the systemic inflammatory responses. We have evaluated the interaction between ILIO and TNF $\alpha$ in promoting the appearance of lupus disease. Our results show a strong association between susceptibility to develop SLE and the high TNF $\alpha$ genotype, independently of IL10 production. However, the highest risk of developing DLE was found among individuals with the combined genotype high IL10/low TNF $\alpha$, probably because of the influence of IL10 levels which cannot be modulated by the low production of $\mathrm{TNF} \alpha$. Furthermore, the high prevalence of discoid lesion observed in SLE patients with this genotype supports this hypothesis. In addition, our results suggest that carriage of the TNF2 allele decreases the risk of developing DLE, favouring the development of SLE or SCLE among those individuals with a high ILl0 producer genotype.

Another interesting finding is the association of autoantibody production with cytokine genotypes. Curiously enough, the highest percentage of anti-Sm antibodies was found among patients genotyped as low IL10/low TNF $\alpha$, a genotype negatively associated with lupus susceptibility. It is known that anti-Sm antibody synthesis is genetically regulated, appearing more often in non-white ethnic groups and in childhood lupus, ${ }^{43}{ }^{44}$ suggesting that SLE susceptibility and anti-Sm synthesis are regulated by different genetic elements. The highest percentage of antibodies to SSa and SSb was found among carriers of the low IL10/high TNF $\alpha$ genotype. This is in accordance with the higher frequency of TNF2 allele found in patients with subacute cutaneous lupus erythematosus, ${ }^{22}{ }^{45}$ congenital heart block, ${ }^{46}$ and cutaneous neonatal lupus, ${ }^{47}$ pathologies linked to the presence of anti-SSa antibodies.

In conclusion, our observations suggest that alleles that regulate constitutive high levels of $\mathrm{TNF} \alpha$ may be a risk factor for SLE, whereas combined IL10/TNF $\alpha$ genotypes affect susceptibility to DLE and could influence different SLE phenotypes. 


\section{ACKNOWLEDGEMENTS}

We are especially grateful to ALAS (Asociación Lúpicos de Asturias) for its continuous encouragement. Supported by Grants PB-MED 0113 from FICYT and PI020481 from FIS.

\section{Authors' affiliations}

A Suárez, P López, C Gutiérrez, Department of Functional Biology, Area of Immunology, University of Oviedo, Oviedo, Spain

L Mozo, Department of Immunology, Hospital Universitario Central de Asturias, Oviedo

\section{REFERENCES}

1 Grondal G, Gunnarsson I, Ronnelid J, Klareskog L, Lundberg I. Cyłokine production, serum levels and disease activity in systemic lupus erythematosus. Clin Exp Rheumatol 2000;18:565-70

2 Park YB, Lee SK, Kim DS, Lee J, Lee CH, Song CH. Elevated interleukin-10 levels correlated with disease activity in systemic lupus erythematosus. Clin Exp Rheumatol 1998; 16:283-8.

3 Horwitz DA, Gray JD, Behrendsen SC, Kubin M, Rengaraju M, Ohtsuka K, et al. Decreased production of interleukin-12 and other Th1-type in patients with recent-onset lupus erythematosus. Arthritis Rheum 1998:41:838-44.

4 Liu TF, Jones BM. Impaired production of IL-12 in systemic lupus erythematosus. II: IL-12 production in vitro is correlated negatively with serum IL-10, positively with serum IFN-gamma and negatively with disease activity in SLE, Cytokine 1998;10:148-53.

5 Aringer M, Feierl E, Steiner G, Stummvoll GH, Hofler E, Steiner CW, et al. Increased bioactive TNF in human systemic lupus erythematosus: associations with cell death. Lupus 2002;11:102-8.

6 Davas EM, Tsirogianni A, Kappou I, Karamitsos D, Economidou I, Dantis PC. Serum IL-6, TNFalpha, p55 srTNFalpha, p75 srTNFalpha, srlL-2alpha levels and disease activity in systemic lupus erythematosus. Clin Rheumatol 1999; 18:17-22.

7 Turner DM, Willians DM, Sankaran D, Lazarus M, Sinnot PJ, Hutchinson IV. An investigation of polymorphism in the interleukin-10 gene promoter. Eur J Immunogenet 1997;24:1-8.

8 Edwards-Smith CJ, Jonsson JR, Purdie DM, Bansal A, Shorthouse C, Powell EE. Interleukin-10 promoter polymorphism predicts initial response of chronic hepatitis C to interferon alfa. Hepatology 1999;30:526-30.

9 Eskdale J, Wordsworth P, Bowman S, Field M, Gallagher G. Association between polymorphisms at the human IL-10 locus and systemic lupus erythematosus. Tissue Antigens 1997;49:635-9.

10 Mehrian R, Quismorio FP, Starssmann G, Stimmler MM, Horwitz DA, Kitridou RC, et al. Synergistic effect between IL-10 and bcl-2 genotypes in determining susceptibility to systemic lupus erythematosus. Arthritis Rheum 1998;41:596-602

11 D'Alfonso S, Rampi M, Bocchio D, Colombo G, Scorza-Smeraldi R, Momigliano-Richardi P. Systemic lupus erythematosus candidate genes in the Italian population: evidence for a significant association with interleukin-10. Arthritis Rheum 2000;43:120-8.

12 Alarcon-Riquelme ME, Lindqvist AK, Jonasson I, Johanneson B, Sandino S, Alcocer-Varela J, et al. Genetic analysis of the contribution of IL- 10 to systemic lupus erythematosus. J Rheumatol 1999;26:2148-52.

13 Johansson C, Castillejo-Lopez C, Johanneson B, Svenungsson E, Gunnarsson I, Frostegard J, et al. Association analysis with microsatellite and SNP markers does not support the involvement of BCL-2 in systemic lupus erythematosus in Mexican and Swedish patients and their families. Genes Immun 2000;1:380-5.

14 Ou TT, Tsai WC, Chen CJ, Chang JG, Yen JH, Wang WS, et al. Genetic analysis of interleukin-10 promoter region in patients with systemic lupus erythematosus in Taiwan. Kaohsiung J Med Sci 1998;14:599-606.

15 Khoa PD, Suiyama T, Yokochi T. polymorphism of interleukin-10 promoter and tumor necrosis factor receptor II in Vietnamese patients with systemic lupus erythematosus. Clin Rheumatol, 2004; Epub ahead of print

16 Lazarus M, Hajeer AH, Turner D, Sinnott P, Worthington J, Ollier WE, et al. Genetic variation in the interleukin 10 gene promoter and systemic lupus erythematosus. J Rheumatol 1997;24:2314-17

17 Rood MJ, Keijsers V, van der Linden MW, Tong TQ, Borggreve SE, Verweij CL, et al. Neuropsychiatric systemic lupus erythematosus is associated with imbalance in interleukin 10 promoter haplotypes. Ann Rheum Dis 1999;58:85-9

18 Mok CC, Lanchbury JS, Chan DW, Lau CS. Interleukin-10 promoter polymorphisms in Southern Chinese patients with systemic lupus erythematosus. Arthritis Rheum 1998:41:1090-5.

19 Dijstelbloem HM, Hepkema BG, Kallenberg CG, van der Linden MW, Keijsers V, Huizinga TW, et al. The R-H polymorphism of Fcgamma receptor lia as a risk factor for systemic lupus erythematosus is independent of singlenucleotide polymorphisms in the interleukin-10 gene promoter. Arthritis Rheum 2002;46: $1125-6$.

20 Crawley E, Woo P, Isenberg DA. Single nucleotide polymorphic haplotypes of the interleukin-10 5' flanking region are not associated with renal disease or serology in Caucasian patients with systemic lupus erythematosus. Arthritis Rheum 1999:42:2017-18.

21 van der Linden MW, Westendorp RG, Stuk A, Bergman W, Huizinga TW. High interleukin- 10 production in first-degree relatives of patients with generalized but not cutaneous lupus erythematosus. J Investig Med 2000;48:327-34.
22 Millard TP, Kondeatis E, Cox A, Wilson AG, Grabczynska SA, Carey BS, et al. A candidate gene analysis of three related photosensitivity disorders: cutaneous lupus erythematosus, polymorphic light eruption and actinic prurigo. Br J Dermatol 2001;145:229-36.

23 Wilson AG, Symons JA, McDowell TL, McDevitt HO, Duff GW. Effects of a polymorphism in the human tumour necrosis alpha promoter on transcriptional activation. Proc Natl Acad Sci USA 1997;94:3195-9.

24 Kroeger KM, Steer JH, Joyce DA, Abraham $\sqcup$. Effects of stimulus and cell type on the expression of the -308 tumour necrosis factor promoter polymorphism. Cytokine 2000;12:110-19.

25 van der Linden MW, van der Slik AR, Zanelli E, Giphart MJ, Pieterman E, Schreuder GM, et al. Six microsatellite markers on the short arm of chromosome 6 in relation to HLA-DR3 and TNF-308A in systemic lupus erythematosus. Genes Immun 2001;2:373-80.

26 Rood MJ, van Krugten MV, Zanelli E, van der Linden MW, Keijsers V, Schreuder GM, et al. TNF-308A and HLA-DR3 alleles contribute independently to susceptibility to systemic lupus erythematosus. Arthritis Rheum 2000;43:129-34.

27 Sullivan KE, Wooten C, Schmeckpeper BJ, Goldman D, Petri MA. A promoter polymorphism of tumor necrosis factor alpha associated with systemic lupus erythematosus in African-Americans. Arthritis Rheum 1997;40:2207-11.

28 Parks CG, Pandey JP, Dooley MA, Treadwell EL, St Clair EW, Gilkeson GS, et al. Genetic polymorphisms in tumor necrosis factor (TNF)-alpha and TNF-beta in a population-based study of systemic lupus erythematosus: associations and interaction with the interleukin-lalpha-889 C/T polymorphism. Hum Immunol 2004;65:622-31.

29 Zuniga J, Vargas-Alarcon G, Hernandez-Pacheco G, Portal-Celhay C, Yamamoto-Furusho JK, Granados J. Tumor necrosis factor-alpha promoter polymorphisms in Mexican patients with systemic lupus erythematosus (SLE) Genes Immun 2001;2:363-6.

30 Tsuchiya N, Kawasaki A, Tsao BP, Komata T, Grossman JM, Tokunaga K. Analysis of the association of HLA-DRB1, TNFalpha promoter and TNFR2 (TNFRSF1B) polymorphisms with SLE using transmission disequilibrium test. Genes Immun 2001;2:317-22.

31 Tan EM, Cohen AS, Fries JF, Masi AT, McShane DJ, Rothfield NF, et al. The 1982 revised criteria for the classification of systemic lupus erythematosus. Arthritis Rheum 1982;25:1271-7.

32 Johnson VJ, Yucesoy B, Luster MI. Genotyping of single nucleotide polymorphisms in cytokine genes using real-time PCR allelic discrimination technology. Cytokine 2004:27:135-41.

33 Korner H, Cretney E, Wilhelm P, Kelly JM, Rollinghoff M, Sedgwick JD, et al. Tumor necrosis factor sustains the generalized lymphoproliferative disorder (gld) phenotype. J Exp Med 2000;191:89-96.

34 Utz PJ, Hottelet M, Schur PH, Anderson P. Proteins phosphorylated during stress-induced apoptosis are common targets for autoantibody production in patients with systemic lupus erythematosus. J Exp Med 1997; 185:843-54.

35 Rosen A, Casciola-Rosen L. Autoantigens as substrates for apoptotic proteases: implications for the pathogenesis of systemic autoimmune disease. Cell Death Differ 1999;6:6-12.

36 Manna SK, Mukhopadhyay A, Aggarwal BB. IFN- $\alpha$ suppresses activation of nuclear transcription factors NF- $\kappa$ B activator protein 1 and potentiates TNFinduced apoptosis. J Immunol 2000;165:4927-34.

37 Baechler EC, Batliwalla FM, Karypis G, Gaffney PM, Ortmann WA, Espe KJ, et al. Interferon inducible gene expression signature in peripheral blood cells of patients with severe lupus. Proc Natl Acad Sci USA 2003;100:2610-15.

38 D'Alfonso S, Rampi M, Rolando V, Giordano M, Momigliano-Richiardi P. New polymorphisms in the IL-10 promoter region. Genes Immun 2000;1:231-3

39 Tone M, Powell MJ, Tone Y, Thompson SAJ, Waldmann H. IL-10 gene expression is controlled by the transcription factors Spl and Sp3. J Immunol 2000; 165:286-91.

40 Grewe M, Gyufko K, Krutmann J. Interleukin-10 production by cultured human keratinocytes: regulation by ultraviolet $B$ and ultraviolet $A 1$ radiation. J Invest Dermatol 1995; 104:3-6.

41 Scholzen T, Hartmeyer M, Fastrich M, Brzoska T, Becher E, Schwarz T, et al. Ultraviolet light and interleukin-10 modulate expression of cytokines by transformed human dermal microvascular endothelial cells (HMEC-1). J Invest Dermatol 1998:111:50-6.

42 Llorente L, Richaud-Patin Y, Garcia-Padilla C, Claret E, Jakez-Ocampo J, Cardiel MH, et al. Clinical and biologic effects of anti-interleukin-10 monoclonal antibody administration in systemic lupus erythematosus. Arthritis Rheum 2000;43:1790-800.

43 Hochberg MC, Boyd RE, Ahearn JM, Arnett FC, Bias WB, Provost TT, et al Systemic lupus erythematosus: a review of clinico-laboratory features and immunogenetic markers in 150 patients with emphasis on demographic subsets. Medicine (Baltimore) 1985:64:285-95.

44 Lopez P, Mozo L, Gutierrez C, Suarez A. Epidemiology of systemic lupus erythematosus in a Northern Spanish population: gender and age influence on immunological features. Lupus 2003; 12:860-5.

45 Werth VP, Zhang W, Dortzbach K, Sullivan K. Association of a promoter polymorphism of tumor necrosis factor-alpha with subacute cutaneous lupus erythematosus and distinct photoregulation of transcription. J Invest Dermatol 2000;1 15:726-30.

46 Clancy RM, Backer CB, Yin X, Kapur RP, Molad Y, Buyon JP. Cytokine polymorphisms and histologic expression in autopsy studies: contribution of TNF-alpha and TGF-beta 1 to the pathogenesis of autoimmune-associated congenital heart block. J Immunol 2003;171:3253-61

47 Clancy RM, Backer CB, Yin X, Chang MW, Cohen SR, Lee LA, et al. Genetic association of cutaneous neonatal lupus with HLA class II and tumor necrosis factor a. Arthritis Rheum 2004;50:2598-603. 